\title{
A series of patients with adolescent idiopathic scoliosis treated with a Rigo System Chêneau (RSC) brace. Primary correction in brace improved by technical evolution
}

\author{
Manuel Rigo
}

Address: E.Salvá Spinal Deformities Rehabilitation Institute, Vía Augusta 185, 08021 Barcelona, Spain

Email: Manuel Rigo - lolo_rigo@hotmail.com

from 4th International Conference on Conservative Management of Spinal Deformities

Boston, MA, USA. 13-16 May 2007

Published: 12 October 2007

Scoliosis 2007, 2(SuppI I):SII doi:I0.II86/I748-7I6I-2-SI-SII

This abstract is available from: http://www.scoliosisjournal.com/content/2/SI/SII

(c) 2007 Rigo; licensee BioMed Central Ltd.

\section{Objective}

To compare the current primary correction in brace with that achieved in a previous series [1], after gaining personal experience and forcing a technical evolution of the original Chêneau technique.

\section{Study design}

Retrospective unselected case series of thirty-two patients (29 females, 3 males) with adolescent idiopathic scoliosis (AIS). The mean age for the group was $12 \pm 1.2$ years, mean Risser was $0.7 \pm 1.1$ and mean Cobb angle was 34.1 \pm 7.1 degrees. Only those patients receiving brace treatment for the first time were included, in order to minimize the influence of factors other than technical changes. They were matched to those from the previous series $(\mathrm{n}=$ $66,12 \pm 2.1$ years, Risser $0.8 \pm 1.1$, Cobb angle $32.8 \pm 9.4$ degrees). All the patients treated during years 2005-2006 and fulfilling the following inclusion criteria were included: 1 . First brace; 2 . A diagnosis of AIS; 3. Age: 1014 years; Risser $0-3$; Cobb angle $>25$ degrees.

\section{Results}

The patients from the present study showed a primary correction of $41.5 \% \pm 16$, which was significantly higher than the previous $32.8 \% \pm 9.4$.

\section{Conclusion}

Primary correction can be improved by both experience and technical evolution based on: 1. Better definition of the passive and active de-rotational mechanism; 2 . More physiological sagittal profile; 3 . Well defined principles of correction, based on curve pattern.

\section{References}

I. Rigo M, Quera-Salvá G, Puigdevall N, Martínez M: Retrospective results in immature idiopathic scoliotic patients treated with a Cheneau brace. Stud Health Technol Inform 2002, 88:24I-245. 